\title{
Feasibility of tailored, selective and effective anticancer chemotherapy by direct injection of docetaxel-loaded immunoliposomes into Her2/neu positive gastric tumor xenografts
}

\author{
YUJI YAMAMOTO ${ }^{1}$, MOTOHIRA YOSHIDA ${ }^{1}$, MITSUNORI SATO ${ }^{2}$, KOICHI SATO ${ }^{1}$, SATOSHI KIKUCHI ${ }^{1}$, \\ HIROKI SUGISHITA $^{1}$, JUN KUWABARA ${ }^{1}$, YUSUKE MATSUNO ${ }^{1}$, YOU KOJIMA ${ }^{1}$, \\ MASAMITSU MORIMOTO ${ }^{1}$, ATSUSHI HORIUCHI ${ }^{1}$ and YUJI WATANABE ${ }^{1}$ \\ ${ }^{1}$ Division of Gastrointestinal Surgery and Surgical Oncology, Department of Surgery, Ehime University Graduate School \\ of Medicine, Shitsukawa, Toon-shi, Ehime 791-0295; ${ }^{2}$ AdMeTech Co., Ltd., Matsuyama, Ehime, Japan
}

Received August 17, 2010; Accepted October 12, 2010

DOI: 10.3892/ijo_00000821

\begin{abstract}
We assessed the effects of direct injection of docetaxel-loaded immuno-(trastuzumab)-liposomes (IDL) on a xenograft mouse tumor model to determine potential clinical applications of intratumoral tailored chemotherapy against Her2/neu-overexpressing gastric cancer. The NCI-N87 Her2/neu overexpressing gastric cancer cell line xenograft mouse model was treated with IDL or docetaxel-loaded liposomes (DL). The ratio of the tumor volume of the treatment:control was determined. In addition, docetaxel pharmacokinetics in tumors were measured using highperformance liquid chromatography, and the cell viability and cell cycle distribution of Her2/neu positive cells were determined by flow cytometric analysis. The IDL group showed a significantly higher distribution of docetaxel in the N87 xenograft tumor tissues and superior antitumor efficacy compared to crude administration of docetaxel and/or trastuzumab and DL. The number of viable Her2/neu positive cells decreased following treatment with either free trastuzumab or IDL. On day 7 after treatment, a decrease in the G0/G1 phase of the cell cycle was observed in the DL and IDL groups compared to the control group. No local adverse effects were observed. These results suggest that intratumoral administration of IDL maintains a high concentration of docetaxel within the tumor leading to a safe and effective regional cancer therapeutic strategy. In addition to the inherent cytotoxic effect of trastuzumab, conjugation of trastuzumab to a liposome further enhanced the retention of docetaxel
\end{abstract}

Correspondence to: Dr Yuji Yamamoto, Division of Gastrointestinal Surgery and Surgical Oncology, Department of Surgery, Ehime University Graduate School of Medicine, Shitsukawa, Toonshi, Ehime 791-0295, Japan

E-mail: yayuji@m.ehime-u.ac.jp

Key words: immunoliposome, Her2/neu positive gastric cancer, trastuzumab, docetaxel within the tumors. These data suggest that immuno-liposome mediated delivery of drugs is a promising new therapeutic option for patients with advanced gastric cancer that overexpress Her2/neu.

\section{Introduction}

In recent studies, Her2/neu overexpression and/or amplification has been observed, not only in breast cancers, but also in colon (1), bladder (2), ovarian (3), endometrial (4), lung (5), uterine cervix (6), head and neck (7), esophageal (8), and gastric carcinomas (9). The Her2/neu protein has also been reported to be overexpressed in 10-30\% of patients with gastric cancer $(9,10)$. These patients are known to be associated with poor outcome and distant metastasis $(11,12)$. Treatment with trastuzumab has been shown to enhance survival rates in breast cancer patients. Nevertheless, the effectiveness of trastuzumab for HER2 positive gastric cancer patients is still controversial.

Docetaxel is one of the most important anticancer drugs used as a standard therapy for various types of solid tumors, such as breast, ovarian, non-small cell lung cancer and advanced gastric cancer. Preclinical studies of docetaxel in combination with trastuzumab demonstrate synergistic interactions of trastuzumab with docetaxel and additive interactions with paclitaxel in breast cancer patients (13).

Higher drug concentrations within the tumor and longer exposure to anticancer drugs will have a greater cytotoxic effect. Intratumoral chemotherapy is an ideal method for the generation of high drug concentrations within solid tumors and for limitation of total body exposure to the cytotoxic agent resulting in increased dose-related cell killing and a reduced systemic toxic effect.

To simultaneously administer both docetaxel and trastuzumab using a single drug delivery system, which may have advantages over their separate administration, we decided to deliver these drugs using liposomes.

Using liposome-mediated delivery of drugs that were selected based on recent advances in chemotherapy, we 
devised a new therapeutic option for advanced gastric cancer using less-invasive and more effective local cancer control than direct administration of conventional anticancer drugs. For this purpose, we investigated the combination of safety, selectivity and anti-cancer effectivity of a monoclonal antibody-conjugated liposome in which an anti-cancer drug was incorporated. The results suggest that monoclonal antibody-liposome mediated tumor delivery of anti-cancer drugs may enhance their anti-tumor effectivity.

\section{Materials and methods}

Reagents. L- $\alpha$-Phosphatidylethanolamine, Dipalmitoyl (DPPE) was obtained from Wako Pure Chemicals (Osaka, Japan). N-succinimidyl-3-(2-pyridyldithio)propionate (SPDP) and cholesterol were purchased from Sigma (St. Louis, MO, USA). 1,2-Dipalmitoyl-sn-Glycero-3-Phosphocholine (DPPC) was from Alexis Biochemicals (Lausen, Switzerland), and Dithiothreitol (DTT) was from Nacalai Tesque (Kyoto, Japan). Docetaxel was provided as a gift by Sanofi-Aventis (Tokyo, Japan). Trastuzumab was a kind gift from Chugai Pharmaceutical (Tokyo, Japan). 3-(2-pyridyldithio)-propionylphosphatidylethanolamine (DTP-DPPE), used as a bridging agent between the lipids and trastuzumab, was prepared by the reaction of SPDP with DPPE as described previously (14).

Preparation of trastuzumab-conjugated docetaxel loaded liposomes. Small unilamellar vesicles were prepared by lipid film hydration and the Sobin extrusion method (15). First, the main ingredients, DPPC, cholesterol, and DTP-DPPE were dissolved in chloroform at a molar ratio of 2:1:0.03 and were mixed in a round-bottomed flask. The solvent was then evaporated using a vacuum in a rotary evaporator until a thin lipid film was formed. The thin lipid film obtained was further dried under vacuum overnight. The thin lipid film was then hydrated using a solution containing an aqueous docetaxel hydrate $(0.5 \mathrm{mg} / \mathrm{ml})$ and 2-[(2-hydroxy-1,1-bis[hydroxymethyl] ethyl)-amino]ethanesulphonic acid (TES) buffer $(10 \mathrm{mM}$, pH 7.4) containing $140 \mathrm{mM} \mathrm{NaCl}, 0.1 \mathrm{mM}$ EDTA and by rotating the flask at about $200 \mathrm{rpm}$ at $40^{\circ} \mathrm{C}$ until the thin lipid film was completely hydrated and a homogeneous dispersion was formed (approximately $30 \mathrm{~min}$ ). The lipid suspension was sonicated for $40 \mathrm{~min}$ in a bath-type sonicator (S-450D, Branson, Atsugi, Japan). The liposome suspension was then extruded under a nitrogen atmosphere through a $100-n m$ polycarbonate membrane filter (Whatman Inc., Piscataway, NJ, USA) using a high-pressure extruder $\left(\right.$ Lipex $^{\mathrm{TM}}$ Extruder, Northern Lipids Inc., Vancouver, Canada).

The trastuzumab to be conjugated to liposomes (thiolbearing trastuzumab) was prepared according to the SPDP method (14). SPDP was added to $1 \mathrm{mg} / \mathrm{ml}$ trastuzumab to a final concentration of $0.1 \mathrm{mM}$, and the mixture was incubated at room temperature for $30 \mathrm{~min}$. DTT was then added to the mixture to a final concentration of $50 \mathrm{mM}$. The mixture was reduced by incubation at room temperature for $20 \mathrm{~min}$. Nonbound SPDP and non-bound DTT were removed by passage through a MicroSpin G-25 column (Amersham Biosciences, Buckinghamshire, UK). Subsequently, thiol-bearing trastuzumab with an exposed $\mathrm{SH}$ radical was prepared in a similar manner.
Trastuzumab-conjugated, docetaxel-containing liposomes were prepared by addition of docetaxel $(0.4 \mathrm{mg} / \mathrm{ml})$ to the liposome suspension containing thiol-bearing trastuzumab, prior to incubation for $16 \mathrm{~h}$ at room temperature. Transmission electron microscopy (JEM-1230, Nihon Denshi, Tokyo, Japan) was also performed to examine the morphologic characteristics of the immunoliposomes.

Animals. Female 4-week-old BALB/c-nu/nu mice were obtained from Charles River Japan (Yokohama, Japan). The maintenance and care of all experimental animals used in this study were carried out according to the guidelines of the Animal Studies Committee of Ehime University, Ehime, Japan. The mice were kept for 1 week in our animal facility prior to tumor inoculation.

Cell culture and culture conditions. The NCI-N-87 (a well differentiated adenocarcinoma) cell line was obtained from the American Type Culture Collection (ATCC, Manassas, VA, USA). This cell line was subcultured in RPMI-1640 medium (Invitrogen, Carlsbad, CA, USA) supplemented with $10 \%$ fetal bovine serum (FBS) and an antibiotic-antimycotic agent containing $100 \mathrm{IU} / \mathrm{ml}$ penicillin and $0.1 \mathrm{mg} / \mathrm{ml}$ streptomycin under standard conditions.

Preparation of the murine subcutaneous tumor model. Logphase NCI-N87 cancer cells were harvested using $1 \mathrm{~mm}$ EDTA in phosphate-buffered saline (PBS), then resuspended at a cell density of $5 \times 10^{7} / \mathrm{ml}$ in PBS containing $500 \mu \mathrm{g} / \mathrm{ml}$ of Matrigel $^{\mathrm{TM}}$ basement membrane matrix (BD Biosciences, San Jose, CA, USA). Each mouse was inoculated by subcutaneous injection of $0.1 \mathrm{ml}$ cells $\left(5 \times 10^{6}\right.$ cells $) /$ mouse or control PBS/ Matrigel into the left flank.

Her2 expression analysis. Tumor xenograft tissues were resected and were processed by formalin fixation and paraffin embedding followed by sectioning. These sections were examined for the expression of HER 2 protein by immunohistochemistry (IHC) using the Hercep Test (Dako Corp., Carpinteria, CA, USA) and for HER2 gene amplification by fluorescence in situ hybridization (FISH) using the PathVysion HER-2 DNA Probe kit (Vysis, Downers Grove, IL, USA). The sections were then analyzed at SRL Medisearch, Inc. (Tokyo, Japan).

Antitumor efficacy. Intratumoral injection therapy of the anticancer agent was started when the tumor had grown to approximately $150-250 \mathrm{~mm}^{3}$. The tumor volume was calculated using the following formula: (tumor volume $\mathrm{mm}^{3}$ ) $=1 / 2 \mathrm{x}$ (long diameter) $\mathrm{x}$ (short diameter) ${ }^{2}$. Antitumor activity was quantified by calculation of the ratio of the tumor volume of the treatment/control $(\mathrm{T} / \mathrm{C})$ using tumor volumes measured on day 21 . Mice were injected only once during the experiment. Tumors of the experimental and control groups were measured 3 times a week.

HPLC analysis. Docetaxel concentrations in the docetaxel loaded liposomes (DL), the trastuzumab-conjugated docetaxel loaded liposomes (IDL), and in tumor samples were quantified using the modified high-performance liquid chromatography 

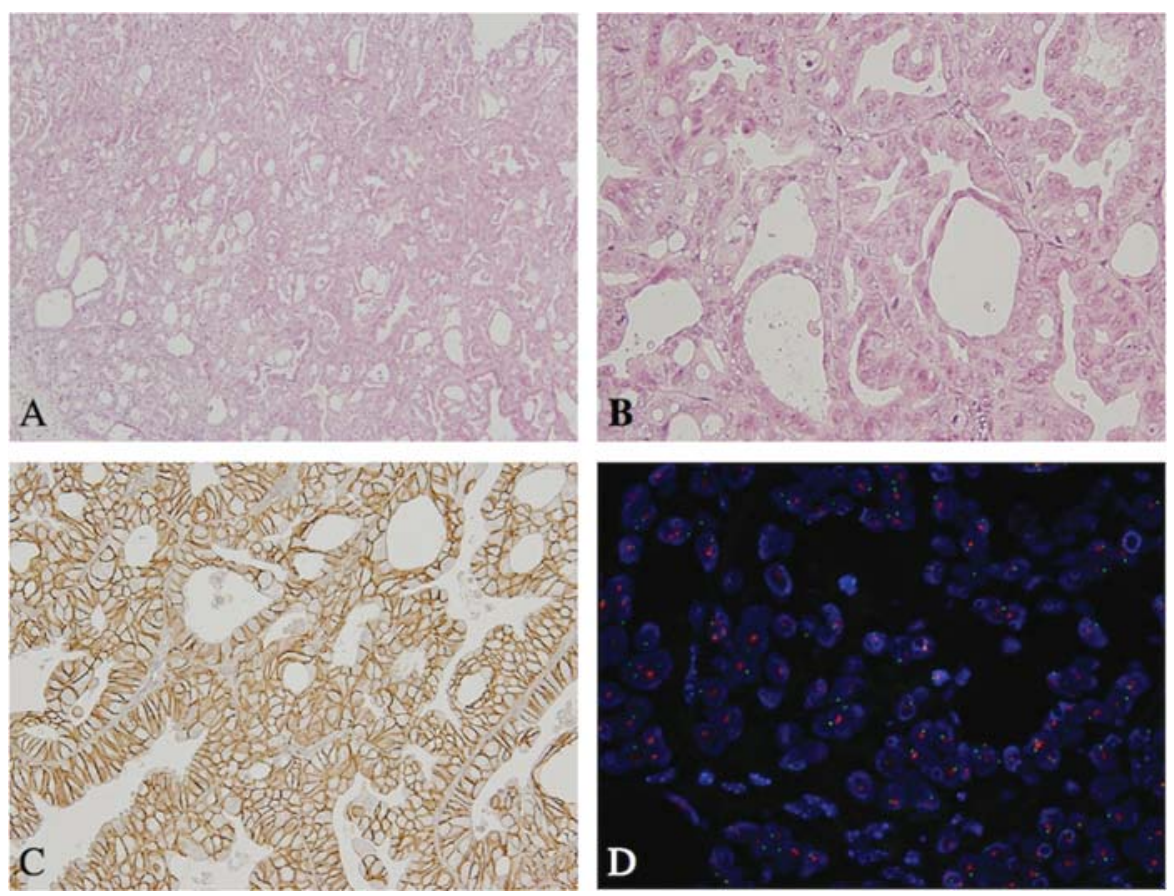

Figure 1. Histology of the NCI-N87 xenograft model. (A and B) H\&E staining. Magnification (A), x100, (B), x400. (C) Immunohistochemistry of the Her2/neu protein. (D) Fluorescence in situ hybridization of the tumor HER2 gene. The HER2/neu probe is colored orange and chromosome 17 is green.

(HPLC) method described by Marchettini et al (16). Briefly, samples were diluted using a sufficient amount of acetonitrile and were homogenized. After centrifugation, the extract was placed into another tube and was evaporated to dryness under nitrogen gas. The residue was resuspended in $250 \mu 1$ of an isocratic mixture of acetonitrile and $0.1 \%$ phosphoric acid in deionized water. These resuspensions were filtered, and $25 \mu \mathrm{l}$ of the filtrate were injected into the HPLC system (665A-11, Hitachi, Tokyo, Japan) at a flow rate of $0.8 \mathrm{ml} / \mathrm{min}$. A reverse phase ODS column (TSK GEL, ODS 80Ts, Tosoh, Tokyo, Japan), was used, and docetaxel concentration was determined by measurement of UV adsorption at $227 \mathrm{~nm}$ using a spectrophotometer (SPD6A, Shimadzu, Kyoto, Japan) connected to the HPLC system.

Flow cytometry. A FACSCalibur flow cytometer (BD Biosciences) was used for all of the flow cytometric analyses. The Neu 24.7-FITC antibody (BD Biosciences) was used to analyze cell surface Her2/neu expression. Cells $\left(1 \times 10^{6}\right)$ were blocked in Pharmingen Stain Buffer (BD Biosciences) for $10 \mathrm{~min}$ on ice and were subsequently incubated with the appropriate antibody for $20 \mathrm{~min}$. After two washes, the cells were resuspended in Pharmingen Stain Buffer containing 7Amino-actinomycin D (BD Biosciences), which was used to discriminate between live and dead cells.

Flow cytometric cell cycle analyses and detection of apoptotic cells were performed using the CycleTest ${ }^{\mathrm{TM}}$ Plus DNA Reagent kit (BD Biosciences). In brief, $5 \times 10^{5}$ cells were prepared and trypsin buffer was then added to each sample and was reacted for $10 \mathrm{~min}$ at room temperature. Trypsin inhibitor and RNase buffer were then added to each sample and were reacted for $10 \mathrm{~min}$ at room temperature. Finally, propidium iodide stain buffer was added to each sample and was incubated for $10 \mathrm{~min}$ in the dark on ice.
Statistical analysis. All statistical analyses were performed using GraphPad Prism software (GraphPad Software, San Diego, CA, USA). The Mann-Whitney U test was used to obtain statistical differences. Statistical significance was established at $\mathrm{p}<0.05$.

\section{Results}

HER2 levels in NCI-N87 cells. We first assayed the level of HER2 protein in the NCI-N87 model cell line by IHC using the HercepTest. Positively stained cells were scored for HER2 protein expression on a scale of 0 to $3+$. The NCI-N87 cells had a score of $3+$. The level of HER2 gene amplification in NCI-N87 cells was determined by FISH analysis. The FISH score was 3.8 signals/cell (Fig. 1).

Characterization of liposomes and immunoliposomes. Characterization of DL and IDL by dynamic light scattering (data not shown) indicated that the average diameter of both liposomes was about $100 \mathrm{~nm}$. The amount of docetaxel incorporated into DL and IDL was $0.43 \pm 0.05 \mathrm{mg} / \mathrm{ml}$, $0.43 \pm 0.03 \mathrm{mg} / \mathrm{ml}(\mathrm{n}=3)$, respectively, as measured by HPLC. The amount of trastuzumab incorporated into IDL was $2.15 \pm 0.17 \mathrm{mg} / \mathrm{ml}(\mathrm{n}=3)$ as measured using the Pierce $660 \mathrm{~nm}$ Protein Assay (data not shown). Based on transmission electron microscopy analysis, each IDL conjugated from two to four antibodies (Fig. 2).

Tumor response following intratumoral injection of docetaxel with PBS, docetaxel and trastuzumab, free liposomes, $D L$ or IDL in the NCI-N87 xenograft model. For assay of the effectivity of liposome-incorporated drugs against the NCI-N87 mouse xenograft tumor model, the mice were randomly assigned to one of 6 treatment groups ( $n=6$ in each group). 


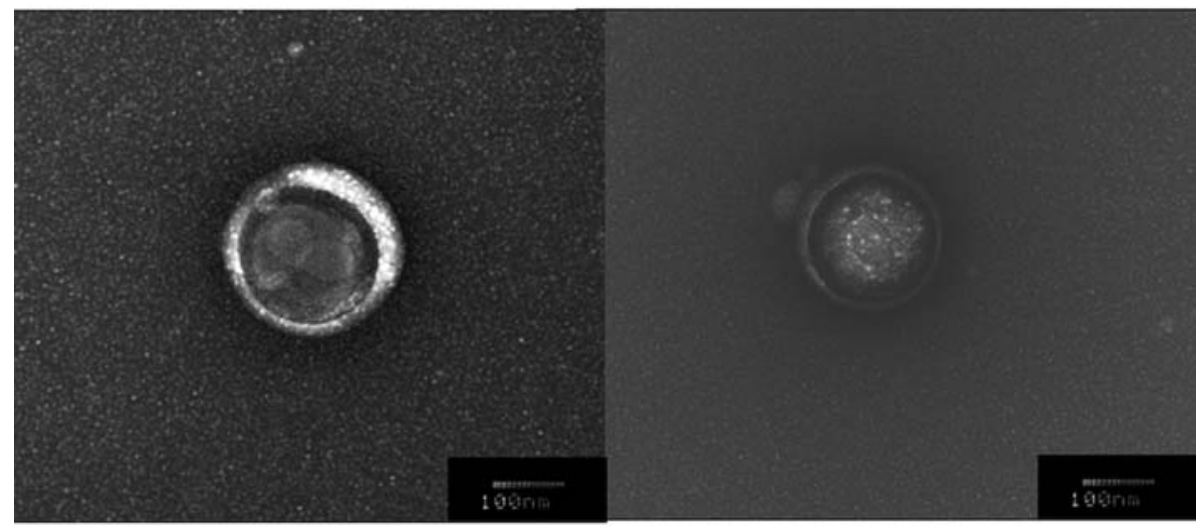

Figure 2. Transmission electron microscopy (TEM) of liposomes. TEM of a representative docetaxel loaded liposome (left) and an immunoliposome (right) is shown. Two to four antibodies were conjugated to each immunoliposome.

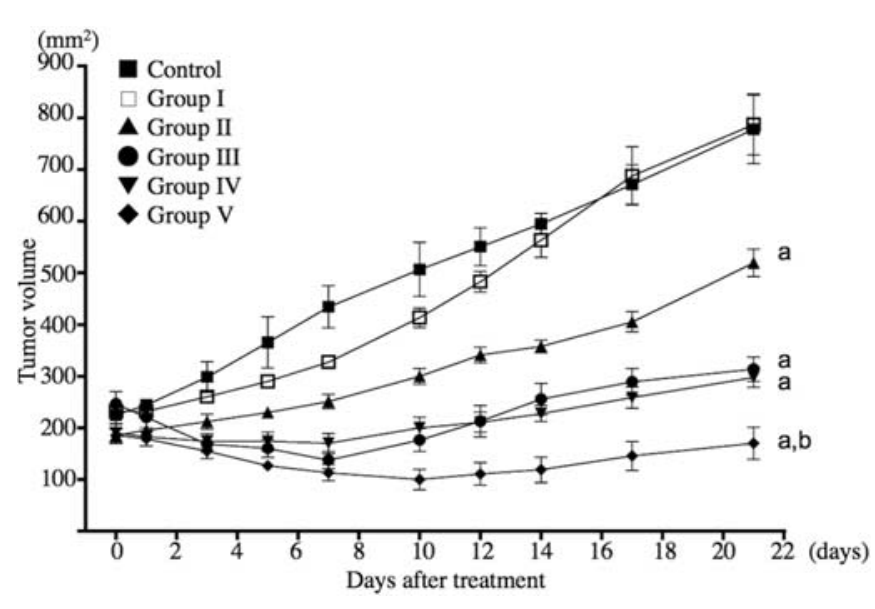

Figure 3. Effect of liposomes on tumor volume. Mice were injected intratumorally with $0.5 \mathrm{ml}$ of either PBS (control group), free liposomes (group I), $1 \mathrm{mg} / \mathrm{kg}$ docetaxel (group II), $1 \mathrm{mg} / \mathrm{kg}$ docetaxel and $5 \mathrm{mg} / \mathrm{kg}$ trastuzumab (group III), $1 \mathrm{mg} / \mathrm{kg}$ DL (group IV, docetaxel-liposomes) or $1 \mathrm{mg} / \mathrm{kg}$ IDL (group V, docetaxel/trastuzumab-liposomes). Tumor volume was measured on the indicated days over 21 days. ${ }^{a} \mathrm{P}<0.05$ vs. control group, ${ }^{b} \mathrm{P}<0.05$ vs. group III; bars indicate the mean \pm SEM.

The groups were injected intratumorally with $0.5 \mathrm{ml}$ of either PBS (control group), free liposomes (group I), $1 \mathrm{mg} / \mathrm{kg}$ docetaxel (group II), $1 \mathrm{mg} / \mathrm{kg}$ docetaxel and $5 \mathrm{mg} / \mathrm{kg}$ trastuzumab (group III), $1 \mathrm{mg} / \mathrm{kg}$ DL (group IV, docetaxel-liposomes) or $1 \mathrm{mg} / \mathrm{kg}$ IDL (group V, docetaxel/trastuzumab-liposomes). Twenty-one days later, tumor volume was measured and the $\mathrm{T} / \mathrm{C}$ ratio was calculated. The T/C ratio was 1.013 for group I, 0.668 for group II, 0.404 for group III, 0.383 for group IV and 0.169 for group V. Thus, the antitumor activity of IDL (group V) was significantly superior to that of the other groups (Fig. 3). No significant decrease in body weight was observed for any of the xenograft model groups (data not shown).

Concentration of docetaxel within tumors. The pharmacokinetic $(\mathrm{PK})$ profile of docetaxel after intratumoral injection was followed by sampling the tumors in groups II, III, IV, and $\mathrm{V}$ at 24,72 and $168 \mathrm{~h}$, followed by measurement of the

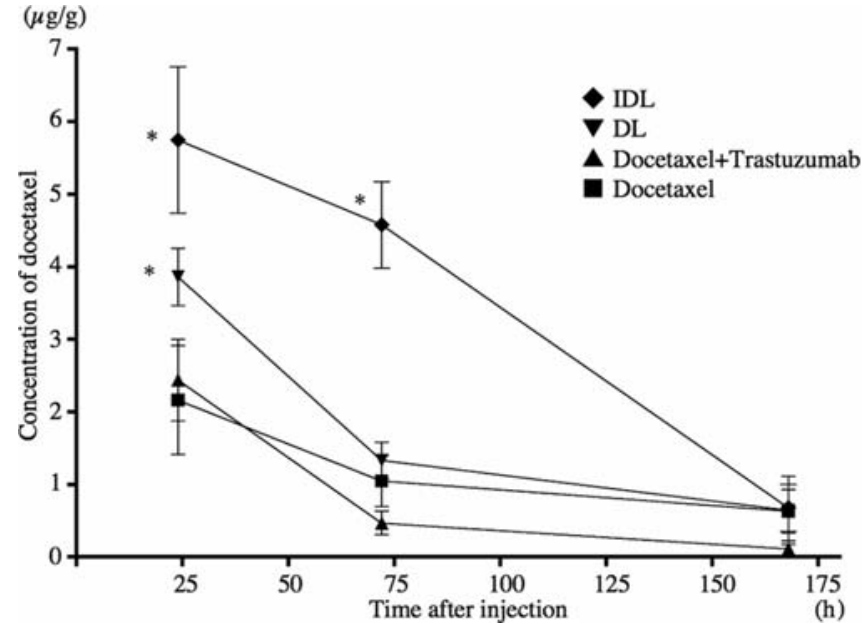

Figure 4. The pharmacokinetic (PK) profile of docetaxel after intratumoral injection. Tumors were sampled at 24,72 and $168 \mathrm{~h}$ following injection of $1 \mathrm{mg} / \mathrm{kg}$ free docetaxel, docetaxel-loaded liposomes (DL) or $1 \mathrm{mg} / \mathrm{kg}$ docetaxel plus $5 \mathrm{mg} / \mathrm{kg}$ trastuzumab either free, or as liposomes (IDL). Docetaxel concentrations were measured using HPLC. Statistically significant data $(\mathrm{P}<0.05)$ vs. the result of the free docetaxel group are indicated by asterisk. Bars indicate the mean \pm SEM.

docetaxal level using HPLC. Tumor concentrations of docetaxel are shown in Fig. 4. The IDL group demonstrated much higher retention of docetaxel within the tumor than the other groups at 24 and $72 \mathrm{~h}$ after injection. The DL group demonstrated much higher retention of docetaxel within the tumor than the free docetaxel or the free docetaxel and trastuzumab groups at $24 \mathrm{~h}$ after injection. However, no significant differences were observed between the groups $168 \mathrm{~h}$ after injection.

Tumor cell viability. The effect of treatment on the viability of the Her2/neu positive NCI-N87 cells in the tumor xenograft was determined by flow cytometric analysis of single cell suspensions of the tumors of the 6 treatment groups. The groups treated with free docetaxel and trastuzumab or with IDL displayed a significant reduction in the percentage of viable Her2/neu positive cells compared to the control group 7 days after treatment. Treatment with a single agent, either 


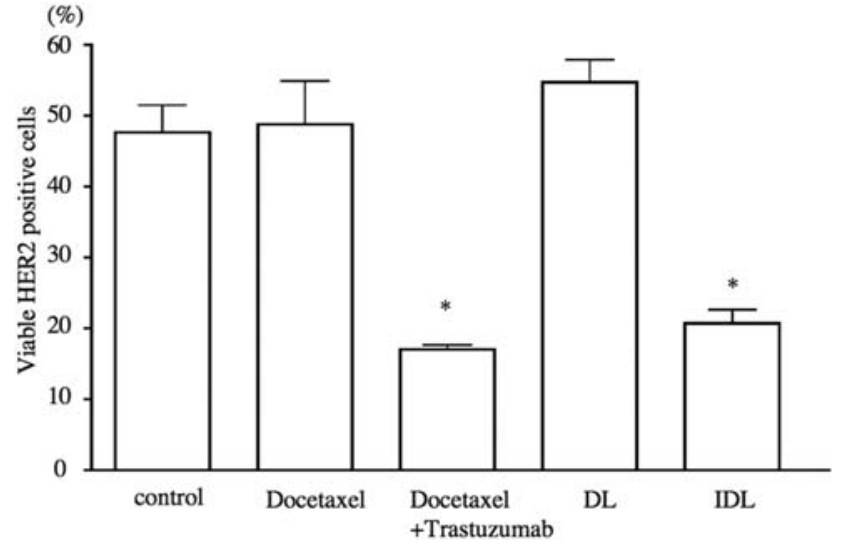

Figure 5. Effect of liposomes on the viability of Her2/neu positive cells. The effect of free, or liposome-formulated Docetaxel, or Docetaxel plus Trastuzumab on the viability of Her2/neu positive cells in single cell suspensions obtained from the NCI-N87 tumor xenograft model was determined by flow cytometric analysis using Pharmingen Stain Buffer containing 7-Aminoactinomycin D. Statistically significant data $(\mathrm{P}<0.05)$ vs. the result of the control group are indicated by asterisk. Bars indicate the mean \pm SEM.

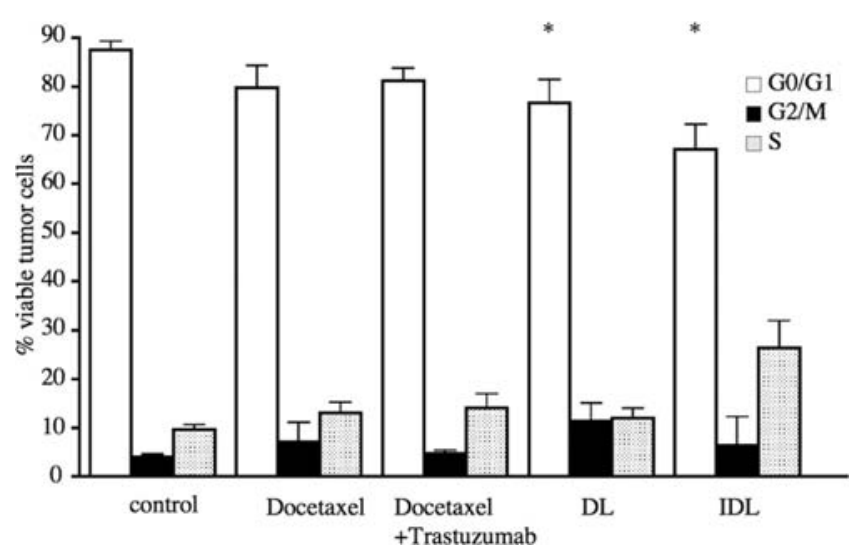

Figure 6. Cell cycle distribution of viable tumor cells. On day 7 after the indicated treatment, tumor cells derived from disaggregated tumors were stained with propidium iodide and were analyzed for DNA content using flow cytometry. Statistically significant data $(\mathrm{P}<0.05)$ vs. the result of the control group are indicated by asterisk. Bars indicate the mean \pm SEM.

free docetaxel or DL, had no significant effect on Her2/neu positive cell viability. These data suggest that the combination of trastuzumab with docetaxel had a significant cytotoxic effect on the tumor of the NCI-N87 xenograft model (Fig. 5).

Effect on cell cycle and cell cycle distribution. To analyze the effect of incorporation of these drugs into liposomes on the cell cycle in tumor cells, the cell cycle distribution of NCIN87 xenografted cells was analyzed on day 7 after each treatment, using FACS analysis (Fig. 6). Both DL and IDL treatment induced a decrease in the number of cells in the G0/G1 phase compared to the control group. The freedocetaxel and the docetaxel plus trastuzumab groups did not show any significant differences. Apoptosis was significantly induced in all treatment groups compared to control (Fig. 7). However, the percentage of apoptotic cells was not significantly different among the different treatment groups.

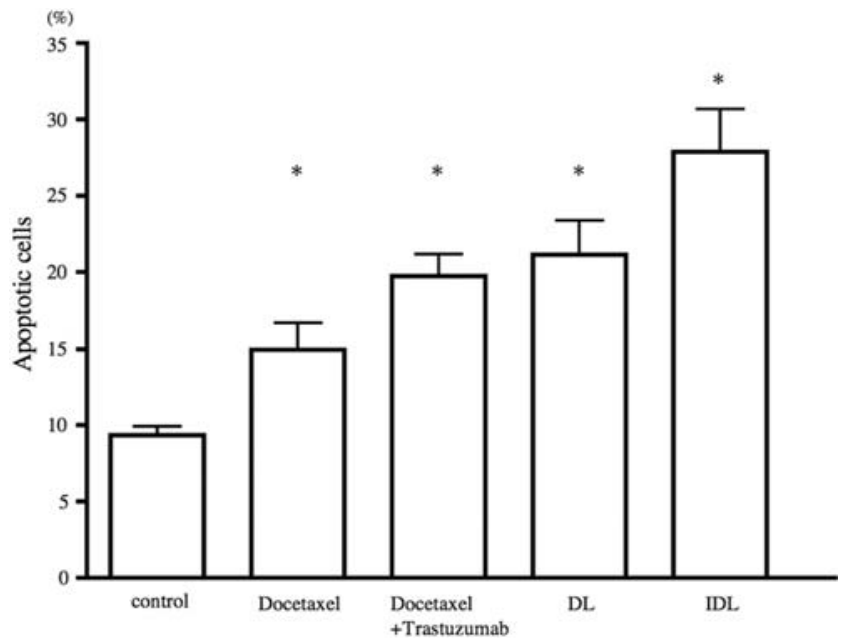

Figure 7. Effect of liposomes on tumor cell apoptosis. On day 7 after the indicated treatment, tumor cells derived from disaggregated tumors were analyzed for apoptosis using flow cytometry and the CycleTest ${ }^{\mathrm{TM}}$ Plus DNA Reagent kit. Statistically significant data $(\mathrm{P}<0.05)$ vs. the result of the control group are indicated by an asterisk. Bars indicate the mean \pm SEM.

\section{Discussion}

There are several potential advantages in using direct intratumoral injection. These advantages include 1) assured precision in the local delivery of drugs, 2) complete perfusion of a drug within and around the lesion, 3) dramatically higher concentrations of the drug within the tumor tissue than is achievable by conventional systemic chemotherapy, and 4) little or no systemic toxic side effects (17).

Fujimoto-Ouchi et al (18) reported that intravenous administration of $60 \mathrm{mg} / \mathrm{kg}$ docetaxel combined with intraperitoneal injection of $20 \mathrm{mg} / \mathrm{kg}$ trastuzumab had effective anti-tumor activity in the NCI-N87 xenograft model. This concentration of docetaxel was considerably higher than that used in the present study. Nevertheless, our study showed effective anti-tumor activity of a lower docetaxel concentration in combination with trastuzumab.

Trastuzumab has been previously shown to have additive/ synergistic interactions with docetaxel for breast cancer treatment (19). Our results are consistent with these previous findings in that trastuzumab interacted at least additively with docetaxel for anti-tumor activity in the NCI-N87 xenograft model.

In a review of intratumoral cancer treatment, Goldberg et al (20) concluded that it is reasonable to believe that preoperative intratumoral chemotherapy using drug carriers that prolong local drug activity is ready to achieve more widespread clinical use. A second approach to the administration of chemotherapeutic drugs for localized tumor treatment could be via a controlled-release implant.

There have been several studies aimed at achieving high intratumoral drug retention. Shikanov et al (21) evaluated the antitumoral activity of a polymeric formulation of paclitaxel administered via an intratumoral injection. They concluded that this polymer formulation of paclitaxel inhibited the growth of tumors. Almond et al (22) reported the in vivo evaluation of the efficacy of an intratumoral injection of mitoxantrone 
both as a free drug and as drug-loaded albumin microspheres. Finally, Bao et al (23) reported the potential use of liposome drug carriers for cancer therapy via direct intratumoral injection. Higher intratumoral retention of the technetium$99 \mathrm{~m}$ (99m Tc)-liposomes was accompanied by improved intratumoral diffusion suggesting that intratumorally administered liposomal drugs are potentially promising agents for solid tumor local therapy.

Liposomes have gained considerable attention as carriers for a wide range of drugs and may have a number of advantages over administration of the free drug. Free docetaxel is solubilized in a polyoxyethylated surfactant prior to injection. A number of biological effects related to the use of this vehicle for the formulation of drugs for clinical use have been described, including acute hypersensitivity reactions and peripheral neuropathy (24). Furthermore, severe skin ulceration may occur during extravasation of docetaxel. Indeed, we found in the present study that percutaneous injection of docetaxel that was diluted in PBS into the tumors of 6 mice resulted in severe skin ulceration in 2 of the mice. However, treatment with liposome-incorporated docetaxel, either DL or IDL, did not induce any skin ulceration. Thus it appears that incorporation of docetaxel into liposomes may reduce the incidence and severity of side effects.

In our study, the liposomes used were approximately $100 \mathrm{~nm}$ in diameter. Wang et al (25) reported that ${ }^{99 \mathrm{~m} T \mathrm{Tc}-}$ cationic liposomes of $100 \mathrm{~nm}$ diameter were retained for a longer period within the tumor than liposomes of larger size. They suggested that smaller liposomes may accelerate intracellular uptake due to greater surface-to-surface contact of the liposomes with the cell membrane. The liposomes used in this study were therefore considered to be of optimal size for tumor uptake and retention.

Active targeting of liposomes to tumor cells is generally attempted by conjugating ligands to the liposomal surface which allow a specific interaction with the tumor cells (26). In our study, the IDL group demonstrated much higher retention of docetaxel within the tumor. This result suggests that HER2 mediated endocytosis is involved in the tumor uptake of IDL and therefore that conjugation of trastuzumab to liposomes is a viable approach for the targeting of liposomes to HER2-expressing tumors. Thus, even in the absence of specific, liposome tumor targeting, liposome incorporation of docetaxel is more effective than treatment with free drugs.

The anti-tumor activity of trastuzumab has been reported to involve two mechanism of tumor growth inhibition a direct anti-proliferative effect (27) and an indirect antitumor effect due to antibody-dependent cellular cytotoxicity (28). In our study, the docetaxel plus trastuzumab group showed much higher inhibition of tumor growth than the docetaxel group. Moreover, the IDL group showed much higher inhibition of tumor growth than the DL group. These data indicate that trastuzumab inhibits tumor proliferation in the NCI-N87 xenograft model. Thus incorporation of trastuzumab into liposomes not only targets the liposomes to the tumor but also has antitumor effects.

In our previous study we observed that docetaxel loaded magnetoliposomes injected locally into a tumor had gradually spread to almost the entire tumor and accumulated in the peripheral lymph nodes. Thus, many Berlin Blue-staining positive magnetic particles were observed in the regional lymph nodes within one day after injection (29). These data indicate that local injection of anticancer drug-containing liposomes of a small size may simultaneously treat regional metastatic lymph nodes and the primary tumor. We now plan to study the effectiveness of IDLs against lymph node metastases in the NCI-N87 xenograft model.

In conclusion, IDL showed good efficacy and limited toxicity as well as excellent anti-tumor properties in a Her2/ neu-overexpressing gastric cancer xenograft model. Studies leading to greater understanding of the biological consequence of Her2/neu directed therapies should allow the integration of this molecular targeted approach with currently available cancer treatments.

\section{Acknowledgements}

We would like to thank Professor Maeyama, M.D., Ph.D., Ehime University Graduate School of Medicine, Department of Informational Biomedicine for his technical advice for HPLC.

\section{References}

1. Schuell B, Gruenberger T, Scheithauer W, Zielinski C and Wrba F: HER 2/neu protein expression in colorectal cancer. BMC Cancer 6: 123, 2006.

2. Eltze E, Wulfing C, Von Struensee D, Piechota H, Buerger H and Hertle L: Cox-2 and Her2/neu co-expression in invasive bladder cancer. Int J Oncol 26: 1525-1531, 2005.

3. McKenzie SJ, DeSombre KA, Bast BS, et al: Serum levels of HER-2 neu (C-erbB-2) correlate with overexpression of p185neu in human ovarian cancer. Cancer 71: 3942-3946, 1993.

4. Hetzel DJ, Wilson TO, Keeney GL, Roche PC, Cha SS and Podratz KC: HER-2/neu expression: a major prognostic factor in endometrial cancer. Gynecol Oncol 47: 179-185, 1992.

5. Hirashima N, Takahashi W, Yoshii S, Yamane T and Ooi A: Protein overexpression and gene amplification of c-erb B-2 in pulmonary carcinomas: a comparative immunohistochemical and fluorescence in situ hybridization study. Mod Pathol 14: 556-562, 2001.

6. Mitra AB, Murty VV, Pratap M, Sodhani P and Chaganti RS: ERBB2 (HER2/neu) oncogene is frequently amplified in squamous cell carcinoma of the uterine cervix. Cancer Res 54: 637-639, 1994.

7. Beckhardt RN, Kiyokawa N, Xi L, et al: HER-2/neu oncogene characterization in head and neck squamous cell carcinoma. Arch Otolaryngol Head Neck Surg 121: 1265-1270, 1995.

8. Reichelt U, Duesedau P, Tsourlakis M, et al: Frequent homogeneous HER-2 amplification in primary and metastatic adenocarcinoma of the esophagus. Mod Pathol 20: 120-129, 2007.

9. Gravalos C and Jimeno A: HER2 in gastric cancer: a new prognostic factor and a novel therapeutic target. Ann Oncol 19: 1523-1529, 2008.

10. Yonemura Y, Ninomiya I, Yamaguchi A, et al: Evaluation of immunoreactivity for erbB-2 protein as a marker of poor short term prognosis in gastric cancer. Cancer Res 51: 1034-1038, 1991.

11. Ross JS and McKenna BJ: The HER-2/neu oncogene in tumors of the gastrointestinal tract. Cancer Invest 19: 554-568, 2001.

12. Tanner M, Hollmen M, Junttila TT, et al: Amplification of HER-2 in gastric carcinoma association with Topoisomerase II alpha gene amplification, intestinal type, poor prognosis and sensitivity to trastuzumab. Ann Oncol 16: 273-278, 2005.

13. Bullock K and Blackwell K: Clinical efficacy of taxanetrastuzumab combination regimens for HER-2-positive metastatic breast cancer. Oncologist 13: 515-525, 2008.

14. Barbet J, Machy P and Leserman LD: Monoclonal antibody covalently coupled to liposomes: specific targeting to cells. J Supramol Struct Cell Biochem 16: 243-258, 1981.

15. Lasic D: From Physics to Applications. Elsevier, Amsterdam p63, 1993. 
16. Marchettini P, Stuart OA, Mohamed F, Yoo D and Sugarbaker PH: Docetaxel: pharmacokinetics and tissue levels after intraperitoneal and intravenous administration in a rat model. Cancer Chemother Pharmacol 49: 499-503, 2002.

17. Celikoglu F, Celikoglu SI and Goldberg EP: Bronchoscopic intratumoral chemotherapy of lung cancer. Lung Cancer 61: 1-12, 2008.

18. Fujimoto-Ouchi K, Sekiguchi F, Yasuno H, Moriya Y, Mori K and Tanaka Y: Antitumor activity of trastuzumab in combination with chemotherapy in human gastric cancer xenograft models. Cancer Chemother Pharmacol 59: 795-805, 2007.

19. Merlin JL, Barberi-Heyob $M$ and Bachmann N: In vitro comparative evaluation of trastuzumab (Herceptin) combined with paclitaxel (Taxol) or docetaxel (Taxotere) in HER2-expressing human breast cancer cell lines. Ann Oncol 13: 1743-1748, 2002.

20. Goldberg EP, Hadba AR, Almond BA and Marotta JS: Intratumoral cancer chemotherapy and immunotherapy: opportunities for nonsystemic preoperative drug delivery. J Pharm Pharmacol 54: 159-180, 2002

21. Shikanov A, Shikanov S, Vaisman B, Golenser J and Domb AJ: Paclitaxel tumor biodistribution and efficacy after intratumoral injection of a biodegradable extended release implant. Int J Pharm 358: 114-120, 2008 .

22. Almond BA, Hadba AR, Freeman ST, et al: Efficacy of mitoxantrone-loaded albumin microspheres for intratumoral chemotherapy of breast cancer. J Control Release 91: 147-155, 2003 .
23. Bao A, Phillips WT, Goins B, et al: Potential use of drug carried-liposomes for cancer therapy via direct intratumoral injection. Int J Pharm 316: 162-169, 2006.

24. Ten Tije AJ, Verweij J, Loos WJ and Sparreboom A: Pharmacological effects of formulation vehicles: implications for cancer chemotherapy. Clin Pharmacokinet 42: 665-685, 2003.

25. Wang SX, Bao A, Phillips WT, et al: Intraoperative therapy with liposomal drug delivery: retention and distribution in human head and neck squamous cell carcinoma xenograft model. Int J Pharm 373, 156-164, 2009.

26. Willis M and Forssen E: Ligand-targeted liposomes. Adv Drug Deliv Rev 29: 249-271, 1998

27. Tokuda Y, Ohnishi Y, Shimamura K, et al: In vitro and in vivo anti-tumour effects of a humanised monoclonal antibody against c-erbB-2 product. Br J Cancer 73: 1362-1365, 1996.

28. Lewis GD, Figari I, Fendly B, et al: Differential responses of human tumor cell lines to anti-p185HER2 monoclonal antibodies. Cancer Immunol Immunother 37: 255-263, 1993.

29. Yoshida M, Watanabe Y, Sato M, et al: Feasibility of chemohyperthermia with docetaxel-embedded magnetoliposomes as minimally invasive local treatment for cancer. Int J Cancer 126: $1955-1965,2010$ 